\title{
Research on Breaker Intelligent Exhaust Device Design $\mathrm{Li} \mathrm{Yi}^{1}{ }^{1 \mathrm{a}^{*}}$, Jiang Hao ${ }^{1}$, Gong Fugao ${ }^{1}$ and Xia Hengyi ${ }^{1}$ \\ ${ }^{1}$ State Grid Chongqing Electric Power Co. Maintenance Branch Company, Chongqing 400039, China \\ aemail: liyijxgs@163.com, bemail:695921336@qq.com, cemail:1639975572@qq.com, demail:1049731389@qq.com
}

Keywords :breaker ;oil pump ;intelligent ;exhaust

Abstract: Aimed at frequent bulge fault of breaker hydraulic operating mechanism, oil pump failure is analyzed, and liquid level sensor and gas sensor are used to design intelligent exhaust device. This device, with neural network self-learning height measurement algorithm as core, processes the data obtained by barometric sensor and liquid level sensor, thus to get accurate oil-level height, realizing real-time control over solenoid valve exhaust device as well as automatic record of system working condition and intelligent identification.

\section{Introduction}

Recently, breaker hydraulic operating mechanism has been widely applied for its small size, large output power, reliability and maintainability.[1] High-voltage circuit breaker adopts hydraulic operating mechanism, but in practical operation the probability of hydraulic operating mechanism fault is relatively high, in which oil pump frequent bulge fault accounts for a relatively large part[2]. If breaker is used for an extended time, there will be some gas aggregated in the oil pump low-pressure section of hydraulic system as well as inside of some high-pressure oil system (energy storage canister and high-pressure oil cylinder).[3,4] The existence of these gases will make oil pump cannot effectively send hydraulic oil from low-pressure section to high-pressure section, thus resulting in shorter oil pump bulge interval time, even the phenomenon that oil pressure does rise with oil pump continuous running[5].

Aimed at breaker operating mechanism fault, intelligent exhaust device is designed in the present paper, in which liquid level sensor and gas sensor are applied to detect breaker, automatically identify oil pump gas content and liquid level, control breaker solenoid valve, to realize intelligent detection and automatic identification.

\section{Intelligent Exhaust Device Operating Principle}

When there is gas in oil pump of breaker operating mechanism, oil pump cannot effectively send hydraulic oil from low-pressure section to high-pressure section, thus resulting in shorter oil pump bulge interval time, even the phenomenon that oil pressure does rise with oil pump continuous running. [6] To make breaker resume normal operation, gas in the oil pump and high-pressure oil system need be exhausted in time.

Joint detection of liquid level sensor and barometric sensor is employed in intelligent exhaust device. When liquid level sensor is used only, due to its multiple problems, such as mechanical fraction, short service life, narrow measurement range, it cannot measure oil-level height accurately.[7] In practical measurement, oil temperature within the oil pump and its interior pressure are obtained by barometric sensor at first. Then neural algorithm is used to calculate network space to be measured, so relative oil-level height at current measuring point is obtained indirectly. Finally compare this measured value to the oil-level height obtained by liquid level sensor to get accurate oil-level height. When accurate oil-level height is acquired, oil-level height is alternated to control solenoid valve to exhaust. Exhaust when oil level is under the lowest oil-level height set by system, and close solenoid valve when it is above set oil level, shown as Figure 1. 


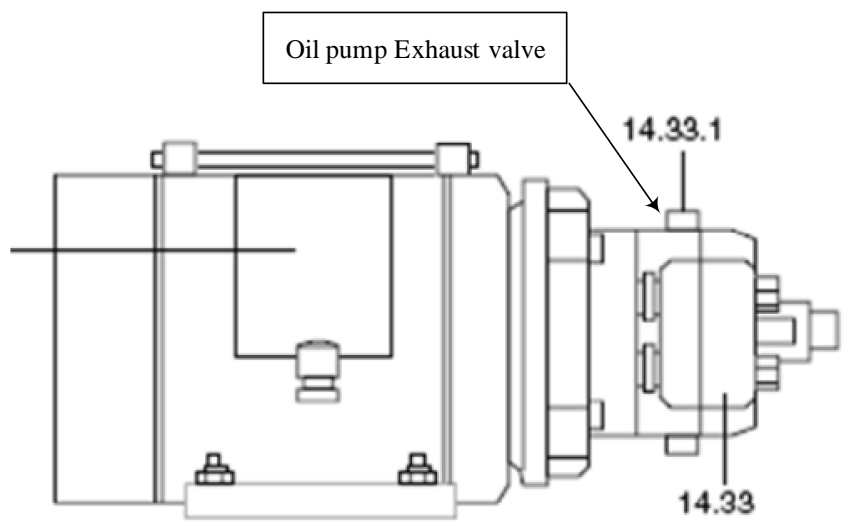

Fig.1 Vent valve of oil pump

Exhaust device is equipped with working condition indicator, fault indicator and buzzer alarm. If abnormal working condition or malfunction is detected by system device through self-checking program, fault indicator will light and buzzer will alarm, and it will enter system protection state. When system resumes normal working condition, alarm will disappear and working indicator will return to normal. In exhaust device, it is also equipped with system data record and data transmission module to record real-time exhaust valve working condition, which helps to understand working characteristics of master device and benefits maintenance.

\section{Intelligent Exhaust Device Hardware Design}

Measurement system process of intelligent exhaust device is as shown in figure 2. The whole measurement system mainly includes sensor module, analog signal modulation circuit, A/D switching circuit, single chip microcomputer processing unit with STM32F103 as core and solenoid valve exhaust device.

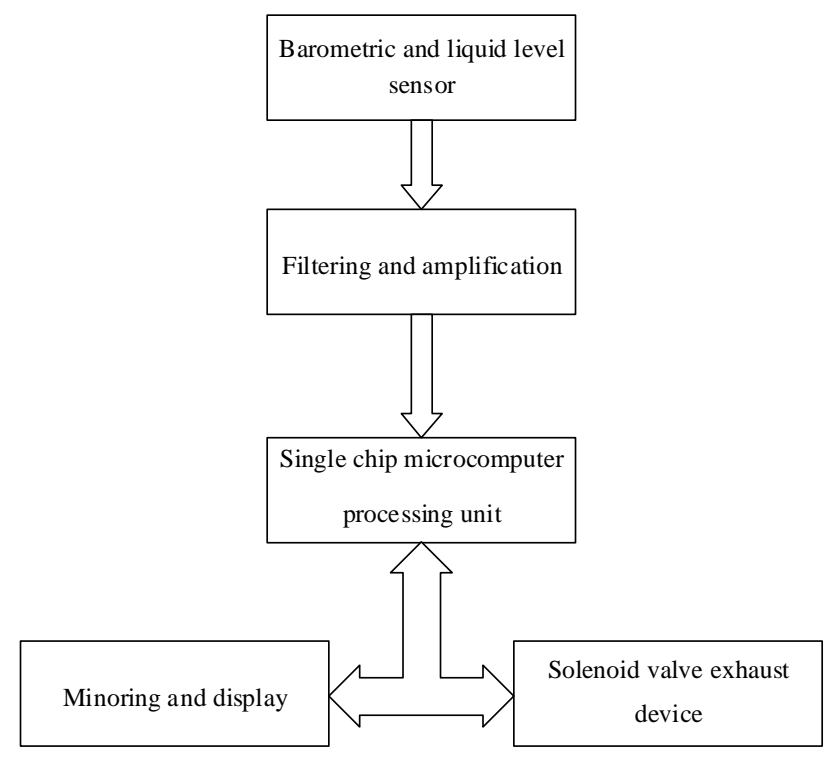

Fig. 2 System Flow Chart

Sensor module is composed of BMP085 digital barometric sensor and liquid level sensor, shown as Figure 3. BMP085 is a digital barometric sensor with high precision and low power consumption, which adopts powerful ceramic leadless chip bearing ultrathin packaging, made up of resistance-type pressure sensor, $\mathrm{AD}$ convertor and control unit. 


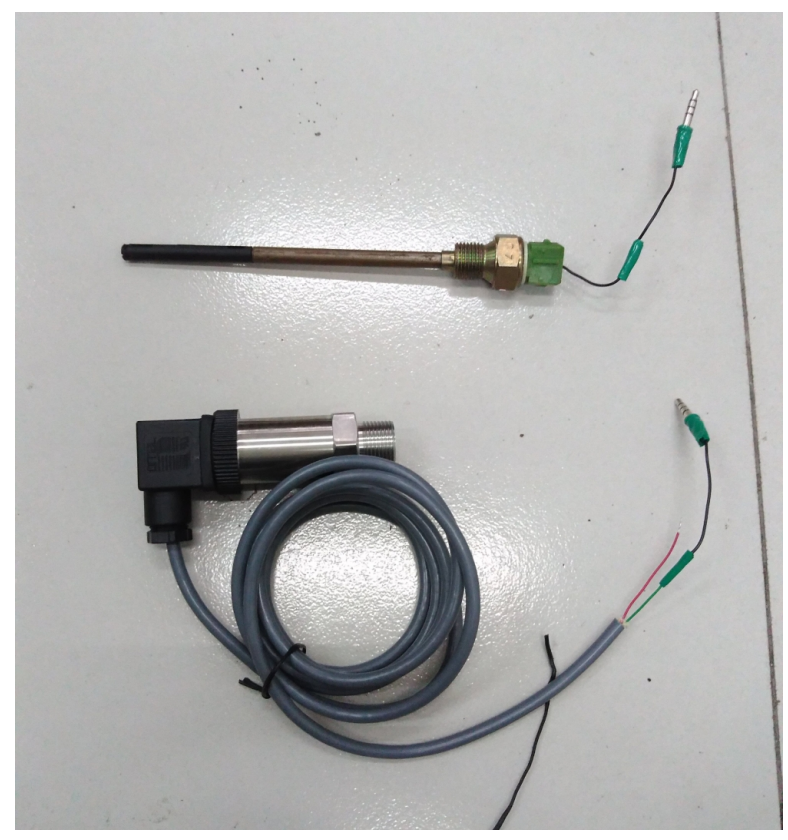

Fig.3 BMP085 digital barometric sensor and liquid level sensor

BMP085 barometric sensor internal temperature compensation is always limited. With combined measurement with liquid level sensor, it can reduce pressure height measuring error due to environmental factors such as temperature, thus to reduce fault operation and improve measurement accuracy.

To guarantee that sensor output signal does not exceed voltage range of analog-digital conversion under relatively high voltage grade, and is higher than the lowest resolution ratio of analog-digital conversion, proportional amplifying circuit is adopted in the design to adjust input signal amplitude, to make its signal within optimal range of $\mathrm{AD}$ conversion, shown as Figure 4. In consideration of that input signal is lower than zero potential, a DC component is superpositioned in input signal in the design.

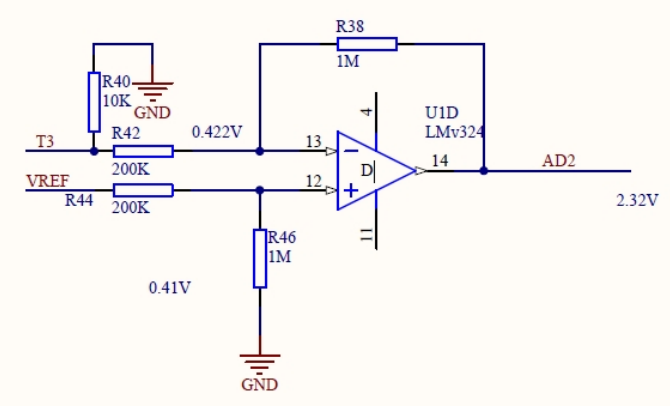

Fig.4 Analog signal conditioning circuit diagram

Single chip microcomputer processing unit takes neural network self-learning height measurement algorithm as core, processes data obtained by barometric sensor and liquid level sensor, to get accurate oil-level height and realize real-time control over solenoid valve module. Single chip microcomputer processing unit is equipped with circuit to automatically record working condition while exhaust valve can automatically conduct relevant operation according to received data.

\section{Implementation Plan}

After powered on, exhaust device begins self-check, with working condition indicator and fault indicator lit on as well as one-second buzzer. When self-check completes, it immediately enters 
monitoring. When the first entry into working condition, as oil level is under the lowest oil level set by system, system state indicator is lit on with solenoid valve opened and oil level raised. When oil level reaches the highest oil level set by system, system closes solenoid valve with working green light flashing. When abnormal working condition or fault is detected by system through self-checking program, fault light will flash and buzzer will alarm, and device will enter system protection state. After system resumes normal working condition, alarm will disappear with working green light flashing. Intelligent Exhaust Device Working Flow Chart is shown as Figure 5

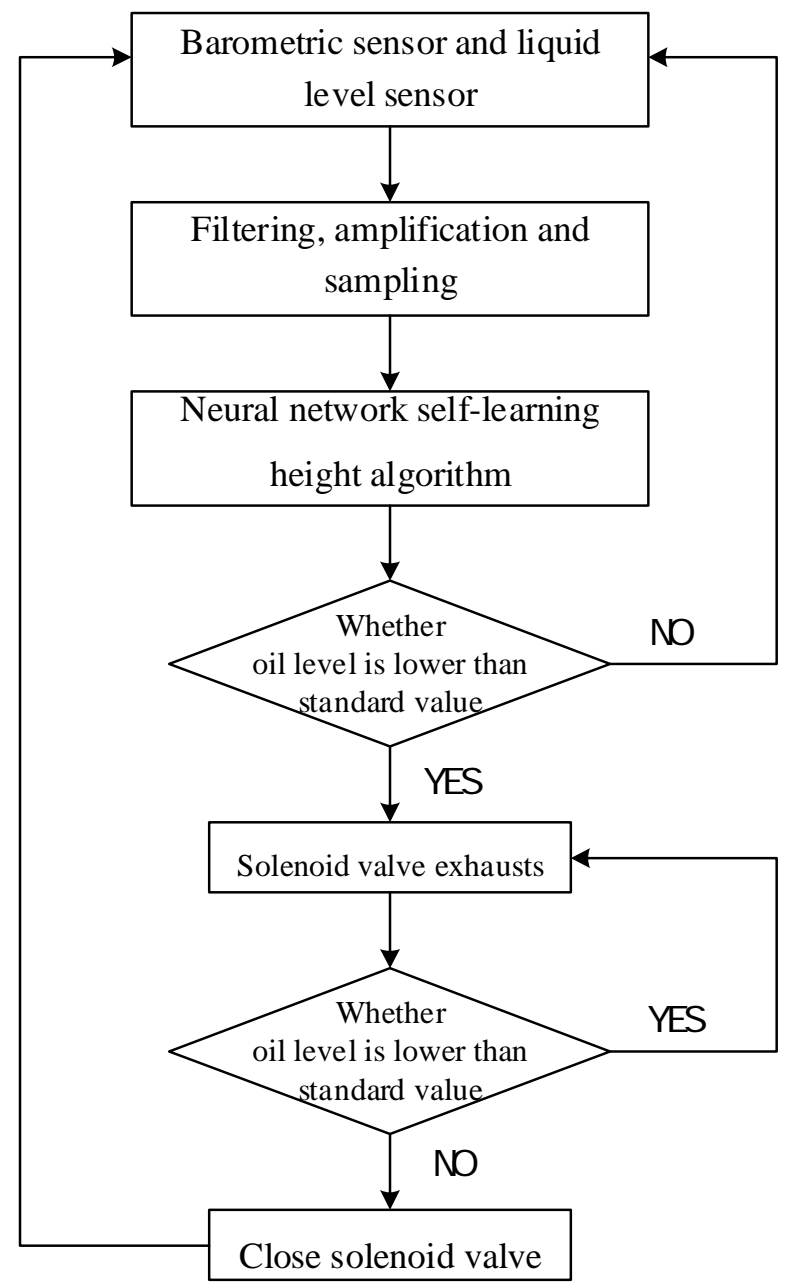

Fig.5 ntelligent Exhaust Device Working Flow Chart

Exhaust breaker intelligent detection device is shown as Figure 6. hen exhaust solenoid valve system data record and data transmission module are working, all kinds of system working states will be recorded, and system will also receive the command by handheld data recorder, and send recorded files to it. Exhaust valve data transmission module and portable data recorder can send command and data through photoelectric coded signal, avoiding mutual interference between high-voltage electromagnetic field and other devices, which is secure and reliable. Data can be stored on computer room computer with portable data recorder connected by wired connection. Exhaust valve serial number responds to equipment serial number one-to-one. Comparison of exhaust valve and master equipment working state helps to understand some working characteristics of master equipment, which also benefits master equipment maintenance. 


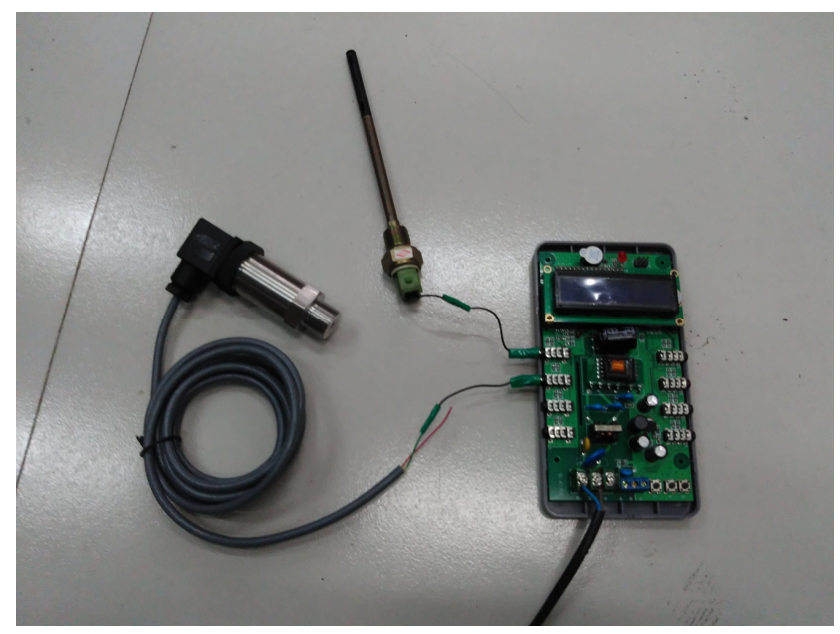

Fig.6 Exhaust breaker intelligent detection device

\section{Conclusion}

Intelligent exhaust device processes the data obtained by barometric sensor and liquid level sensor, thus to get accurate oil-level height, realizing real-time control over solenoid valve exhaust device as well as automatic record of system working condition and intelligent identification.

Combined measurement of gas and liquid level sensor is adopted in intelligent exhaust device, which weakens environmental influence, avoids regular blind manual exhaustion, reduces the danger of maintainer touching high-risk equipment for live working, improves equipment working security and reliability, and significantly improves working efficiency.

\section{References}

[1] Li Haibo, Yu Jun. The Impact of Air Content in Hydraulic System on Hydraulic Mechanism [J]. High-Voltage Apparatus, 1,(2014).

[2] Zhou Xuan. High-Voltage Circuit Breaker Hydraulic Operating Mechanism Common Faults Analysis [J]. Electrotechnical Application, 19,(2011).

[3] Liu Feng, Xia Zhenling, Song Weigong, Yu Guanghui. Analysis on Circuit Breaker Hydraulic Operating Mechanism Common Faults and Treatment [A]. National Engineering Laboratory for Disaster Backup and Recovery, Beijing University of Posts and Telecommunications Information Security Center. The Proceeding of Asia-Pacific Smart Grid and Information Engineering Academic Conference of 2011 [C]. National Engineering Laboratory for Disaster Backup and Recovery, Beijing University of Posts and Telecommunications Information Security Center, 2011.

[4] Zhao Chenguang, Kang Guojun. Breaker Hydraulic Mechanism Common Faults Analysis and Treatment [J]. Electric Appliance Industry,9,(2011).

[5] Li Jianming, Wang Zhiyong, Wang Shuchen. 3AQ/3AT Breaker Hydraulic Mechanism Oil Pump Frequent Bulge Fault Analysis and Treatment [J]. High-Voltage Apparatus, 5,(2011).

[6] Li Zhiyong. High-Voltage Oil-Minimum Breaker Hydraulic Mechanism Faults Diagnosis and Treatment [J]. Chinese High-Tech Enterprises, 25,(2010).

[7] Fan Shouxiang, Yang Maojun. 500kVSF_6 Breaker Hydraulic Mechanism Faults Analysis [J]. East China Electric Power, 2,2000. 